\title{
Drawing the map: The creation and regulation of geographic constraints on shared bikes and e-scooters in San Francisco, CA
}

\author{
Marcel E. Moran \\ University of California, Berkeley \\ moranm@berkeley.edu
}

\begin{abstract}
A prominent question in transportation planning is how cities should regulate emerging modes, such as shared bikes and e-scooters. This pertains to a range of attributes, including pricing, use of the public right of way, number of vehicles in a fleet, and vehicle speeds. However, less attention has been paid to the way private operators spatially constrain access to their fleets, such as via the use of virtual geographic boundaries (hereafter "geofences"), or how municipalities have regulated these features. San Francisco, given it is home to a number of these schemes, presents a compelling case for studying geofences, and how regulators have sought to influence them to further public policy goals, including spatial equity. This study analyzes each bike and e-scooter geofence in San Francisco longitudinally from 2017 to 2019 via manual digitization of all geofences. This reveals high levels of overlap in the city's dense northeast quadrant, with limited to no coverage in western neighborhoods. Each operator's geofence expanded over this period, filling in gaps in the northeast quadrant and expanding outward in each direction. Review of permit guidelines and applications submitted by operators indicate that San Francisco's regulations for geofences have been limited and inconsistent, which may have contributed to the concentration of services in one section of the city, as well as disconnected geofence "islands." Together, these observations demonstrate that if broad geofence coverage (i.e., spatial equity) is an explicit municipal goal, such an aim must prominently feature into the regulatory process. This is particularly important given that operators, if left with freedom over geofence design, are likely to emphasize only a city's densest areas, especially if tight caps are set on the allowed number of vehicles. Finally, this case also exemplifies that geofences are not drawn in a vacuum but instead relate to other permit conditions as well as pressure from community organizations.
\end{abstract}

Keywords: Dockless, bikesharing, e-scooters, micromobility, geofences, transport

\section{$1 \quad$ Introduction}

Today, many large U.S. cities contain new options for ground transportation, at different price points, with different vehicle form factors, and for different lengths and types of trips. These include carshar-

Copyright 2021 Marcel E. Moran

http://dx.doi.org/10.5198/jtlu.2021.1816

ISSN: 1938-7849 | Licensed under the Creative Commons Attribution - Noncommercial License 4.0

The Journal of Transport and Land Use is the official journal of the World Society for Transport and Land Use (WSTLUR) and is published and sponsored by the University of Minnesota Center for Transportation Studies.

\section{Article history:}

Received: June 5, 2020

Received in revised form: August 6, 2020

Accepted: October 7, 2020

Available online: February 2,

2021 
ing programs, as well as shared bicycles, e-scooters, and mopeds (Cohen \& Shaheen, 2016), most of which employ service models that let users rent the vehicle in question for a short period of time, in an on-demand fashion. This broader category of "shared mobility" (or "micromobility" if excluding shared cars) offers a number of benefits to consumers, including not needing to own vehicles in order to use them (which lowers financial barriers), and the ability to make one-way trips. For these reasons, many cities have embraced shared modes, including via direct subsidies of private operations (Yanocha et al., 2018), partnerships around station siting (Sherwood \& Murphy, 2014), and management of public schemes (Lohry \& Yiu, 2015).

Along with such benefits, shared mobility has also brought with it a number of drawbacks for municipalities, users, and residents. These include technological and financial obstacles to use (Kodransky \& Lewenstein, 2014), issues over data sharing and privacy (Somenahalli, Meng, Sleep, \& Berry, 2019), injuries to riders and pedestrians (Bauer et al., 2020; Sikka, Vila, Stratton, Ghassemi, \& Pourmand, 2019), and in the case of shared bikes and e-scooters, the potential for sidewalk cluttering (Wood, Bradley, \& Hamidi, 2019). However, one of the least-studied aspects of these services are their geographic constraints. Station-based bikeshare schemes manage this via the location of stations - physical installations on the street that bikes are withdrawn from at the beginning of trips and must be deposited at the end of trips (Shaheen, Martin, Chan, Cohen, \& Pogodzinski, 2014). In this way, a bikeshare scheme can only grow spatially as does its network of stations. In contrast, floating schemes of shared bikes and e-scooters employ "geofences" or virtual geographic boundaries which are presented to users within each operator's smartphone application as polygons overlaid on city maps. Broadly, the purpose of this study is to understand how geofences are constructed by private operators, how such boundaries change over time, and what the role of municipal regulators is in influencing those geofences.

Geofences, rather than stations, dictate the area where shared bike or e-scooters can be located to begin a trip, and where they must be parked within when trips end. One hypothesis for operator behavior is that they set geofences in such a way that covers an area of a city in which there is high density and/ or regions of interest (e.g., tourist locations) which can generate enough trips to make a scheme profitable. Another nuance to this method of constraining the geographic range of vehicle use is that many private operators employ geofences in two complementary ways. First, a large geofence indicates the full range of trip possibilities, and second, at times a series of smaller polygons indicate where parking can occur at the street level, such as showing zones where parking is preferred (e.g., next to rail stations), and where parking should not take place (e.g., on the steps of a public building).

To date, only a handful of studies have considered the role of geofences (Lazarus, Pourquier, Feng, Hammel, \& Shaheen, 2020; Moran, Laa, \& Emberger, 2020; Smith \& Schwieterman, 2019) which belies their fundamental importance in mediating who may or not access these modes. Indeed, how geofences are set by operators, and how they are regulated by municipalities, relates to the active debate among scholars regarding spatial equity (McKenzie, 2020), and merits more analysis. With this context, San Francisco represents an important case, given it is often at the forefront of technological change (including in transport policy; Pierce \& Shoup, 2013), is home to shared e-scooters ${ }^{1}$ and bikes, as well as some of the earliest municipal permits in the U.S for such services (Rudick, 2017).

\footnotetext{
${ }^{1}$ Given the word "scooter" has meant different vehicle types at different times, it is important to distinguish between moped or Vespa-style e-scooters, and powered standing e-scooters, the latter of which this paper will discuss.
} 


\section{$2 \quad$ Literature review}

Shared devices for personal mobility are not new; bikeshare first debuted in the Netherlands in 1965 known as "white bikes," which were free to ride and could be left outside on any street within Amsterdam (van der Zee, 2016). Since then, such schemes have incorporated stations (also called "docks"), which constrain trips geographically (DeMaio, 2009). Over the last decade, the majority of bikeshare schemes in North America, Europe, and Asia were (and remain) station based (Shaheen, Guzman \& Zhang, 2010; Yanocha et al., 2018). For these, the primary spatial decision to be made is where to locate stations. If the overall network of stations can be thought of as comprising a "catchment" area (Fishman, 2020), one approach is to devise that area in order to maximize ridership while staying within the budget for station construction. Scholars investigated the relationship between station siting and use in Paris (which has a large system known as Vélib'), and determined that $80 \%$ of trips come from those whose origins (homes, offices, transit stops) are within 300 meters of a station (Kabra, Belavina, \& Giotra, 2019). This relationship generally has been incorporated into catchment design, by locating planned stations within cities' densest areas. For example, a study of Madrid made use of both residential addresses to identify likely trip origins, and commercial centers to predict likely destinations, with the resulting station recommendations clustered in Madrid's CBD, which represented the highest trip-demand forecast (García-Palomares, Gutiérrez, \& Latorre, 2012).

Though, clustering bikeshare stations within CBDs has been challenged from an equity perspective and relates the larger debate about how new modes should be distributed (Docherty, Marsden, \& Anable, 2018). If bikeshare is meant to provide transportation alternatives to a wide swath of neighborhoods, stations cannot only be placed within office centers or high-end commercial districts. Such bikeshare-planning outcomes can reinforce existing transportation inequities or "transport poverty" across cities (Groth, 2019), which have often left low-income neighborhoods with less access to transit than wealthier ones (Giuliano, 2005; McKenzie, 2013; Welch, 2013) as well as jobs (Andersson, Haltiwanger, Kutzbach, Pollakowski, \& Weinberg, 2018; Blumenberg \& Ong, 2001; Liu \& Kwan, 2020). Indeed, the trade-off between coverage and ridership, in that ridership generally does not increase as coverage expands beyond dense areas is well covered in the literature, not only for bikeshare (Caruso, \& Thomas, 2017; Médard de Chardon), but also for transit (Walker, 2008). Beyond finances, others have noted that the tension between ridership and coverage also relates to environmental sustainability, in that transit systems which are restricted to dense areas (and not outlying peripheries) can be less carbonintensive per rider (Mattioli, 2016).

Scholars have also analyzed how bike infrastructure interacts with gentrification. In "Bike Lanes are White Lanes" (Hoffman, 2016), Hoffman argues that the divergent reception of bike lanes is tied to the bicycle's status as a "rolling signifier." This means that whereas bicycles can signal a sustainability ethic in high-income and predominantly-white neighborhoods, they can simultaneously be read as proof of someone's inability to afford a car in a neighborhood with lower socio-economic status. While Hoffman details some communities that oppose bike infrastructure for fear of gentrification, she argues that such places would likely be more open to bicycle facilities if they are included in such planning from the beginning, rather than if residents' input is only heard at the end of these processes. Lugo (2018) builds on this in "Bicycle/Race," writing that because bicycling advocacy in the U.S. is largely dominated by white people, the gap between "who rides and who speaks for riding" can make bike-lane plans seem like impositions on communities of color. These suppositions can be extended to bikeshare; even if a city believes bikeshare can serve as an affordable transportation option, it may be perceived very differently across neighborhoods.

Since 2015, floating schemes have grown dramatically, led at first by companies such as Ofo and Mobike which developed huge operations in Chinese cities and then spread internationally (Russell, 
2017). This service model presents different spatial questions; rather than a network of fixed stations, geofences serve as spatial constraints. Still, lessons from station-based bikeshare catchment areas hold. A geofence could be drawn solely within a CBD to ensure density of likely users, or it could be set more broadly to provide access to a larger number of neighborhoods. Geofences are not the only component of accessibility (which also include vehicle features, supply of bike lines, and the number of vehicles in a geofence), but their presence is the first step required toward one's ability to participate in a shared scheme.

While floating schemes originally were comprised only of bicycles, e-scooters now represent the fastest-growing segment by a wide margin. Indeed, a NACTO report calculated that in 2018 total U.S. e-scooter rides eclipsed floating bikes by a factor of 4:1, and even exceeded total station-based bike trips (Bliss, 2019). Given floating schemes are newer, scholarship on their operations is more limited. Though, early contributions have provided meaningful results. For example, an analysis of whether or not e-scooters were being parked correctly in San Jose, CA found that just 2\% (11 out of 530) were in any way impeding pedestrians (Fang, Agrawal, Steele, Hunter, \& Hooper, 2018). To this point, a report on best practices for micromobility highlighted the benefit of establishing micromobility-specific parking zones on sidewalks and streets (Shaheen \& Cohen, 2019). In addition, a simulation-based study found that Chicago could benefit significantly from e-scooters given large gaps in its mass transit (Smith $\&$ Schwieterman, 2018). Finally, the first nationwide survey of Americans' perceptions of e-scooters reported favorable opinions from a majority of respondents, across ten cities (Clewlow, 2018). Though, one of the benefits touted in e-scooter marketing - that they can make a city's transportation more sustainable - has come under scrutiny. Indeed, a study identified two components of such schemes that could negate any mode-shift away from cars and toward e-scooters: that operators use gasoline-powered automobiles to collect and rebalance e-scooters, and that high vehicle turnover (due to damage and theft) raises the lifecycle emissions of the entire scheme (Hollingsworth, Copeland, \& Johnson, 2019).

Outside of academia, the Portland Bureau of Transportation released a report on its e-scooter pilot, which included usage statistics and a survey of riders (Orr \& Nebel, 2019). One intriguing result was that $74 \%$ of respondents (riders) had never used the city's station-based bikeshare system, and $42 \%$ had never bicycled in the city. The Washington, D.C., Department of Transportation also produced a report on its experience so far with shared bikes and e-scooters, finding that the latter were ridden more than floating bikes in three of their first four months of availability (Castellanos, 2018). Austin, Texas provides information on e-scooter trips to the public via an online dashboard with aggregate trip counts (Clarke \& Clary, 2019). This data have offered such insights as spikes in ridership during city events (Bradshaw, 2019), and served as a component of a study on scooter-related injuries wherein total trips were used as the denominator for determining the overall injury rate, the Dockless Electric ScooterRelated Injuries Study (Austin Public Health, 2018).

So far, scant attention has been paid to geofences, perhaps in part because they are not visible features on the street (only virtual). Indeed, given geofences vary by operator, comparisons across different permit holders in a city (or across time for a single operator) are difficult to make. Overall, planning and transportation scholars have not yet examined geofences in earnest, including how they are developed, regulated, and contested in urban areas.

\section{$3 \quad$ Material and methods}

Shared bike and e-scooter geofences are simultaneously transparent and opaque. They are transparent in the sense that anyone can view a geofence upon opening a given operator's smartphone application. For example, JUMP's application displays its geofence in San Francisco on top of a reference map, along with the location of each available bike (see Figure 1). 


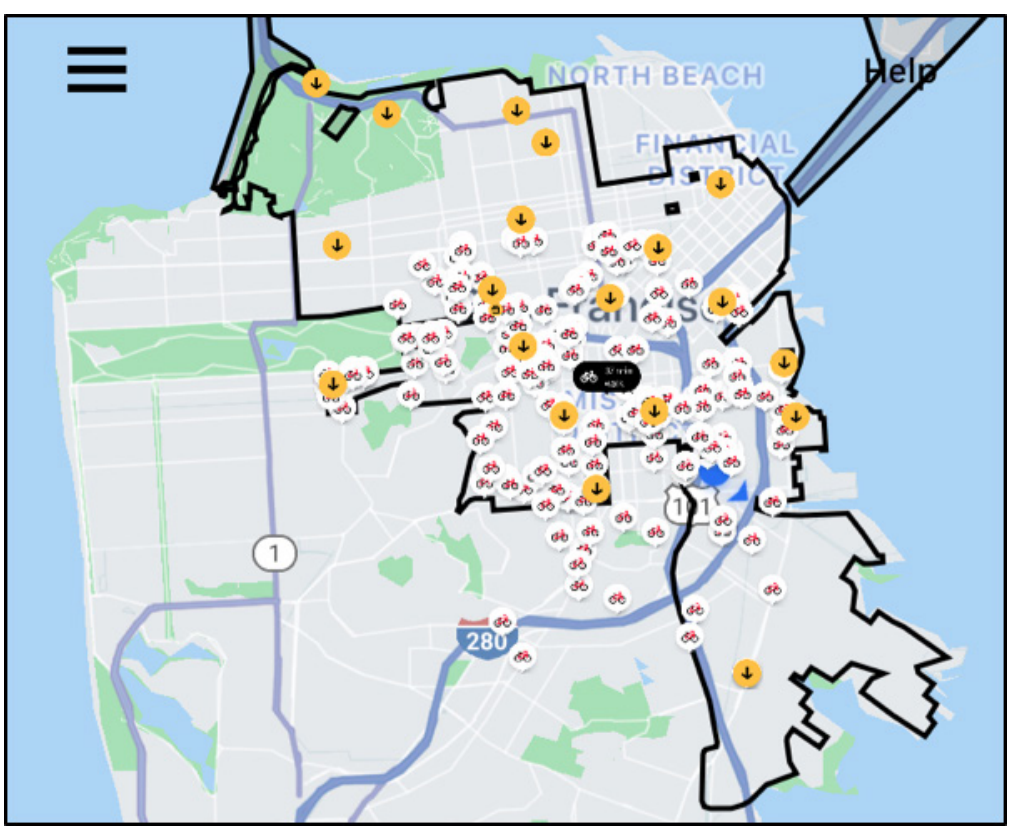

Figure 1. Screenshot of JUMP's smartphone application in San Francisco, which shows available bikes (bike icons), charging stations (yellow icons), and the geofence for vehicle parking (black-outlined polygon)

At the same time, geofences are opaque in the sense that there is usually little information provided as to how they are drawn, including why certain areas are included while others are excluded. Moreover, there is no effort on the part of the public sector to aggregate geofences in one place - such as within a mobile application or an online clearinghouse - which means it is not possible to see how geofences relate to each other across operators, or how geofences for the same operator change over time. In San Francisco there is no way to view geofences for shared bikes and e-scooters other than one at a time within each smartphone application. These two conflicting aspects of geofences - their instant accessibility but deeper barriers to analysis - lead to the research method used for this study: longitudinal tracking of geofences for all shared bike and e-scooter operators.

In terms of micromobility in San Francisco, there are four entities which operated over the 20172019 time frame of this study. Two are bikeshare schemes: Bay Wheels ${ }^{2}$ and JUMP. Bay Wheels, with stations in San Francisco, Oakland, San Jose, and Berkeley launched with the support of the Bay Area's metropolitan planning organization in 2013 (Goebel, 2013). This scheme is operated by Motivate, which was acquired by Lyft in 2018 (Yurieff, 2018). As of September, 2019, Bay Wheels maintained 171 stations in San Francisco, with a combination of pedal and electric-assist bicycles (See Figure 2). The second bikesharing scheme in San Francisco is operated by JUMP, which consists solely of e-bikes (see Figure 3), and has been present in San Francisco since June, 2017 (Pender, 2017). In 2018 it was acquired by Uber (Marshall, 2018; Rudick, 2018a), and in 2020 the ownership was transferred to Lime (Everett, 2020). Given JUMP was entirely constrained by a geofence (not stations), it is the bikeshare scheme of interest for this study.

${ }^{2}$ Known as Ford GoBike until June 2019 (“Introducing Bay Wheels: New Bikes and a New Name,” (Lyft, 2019)). 


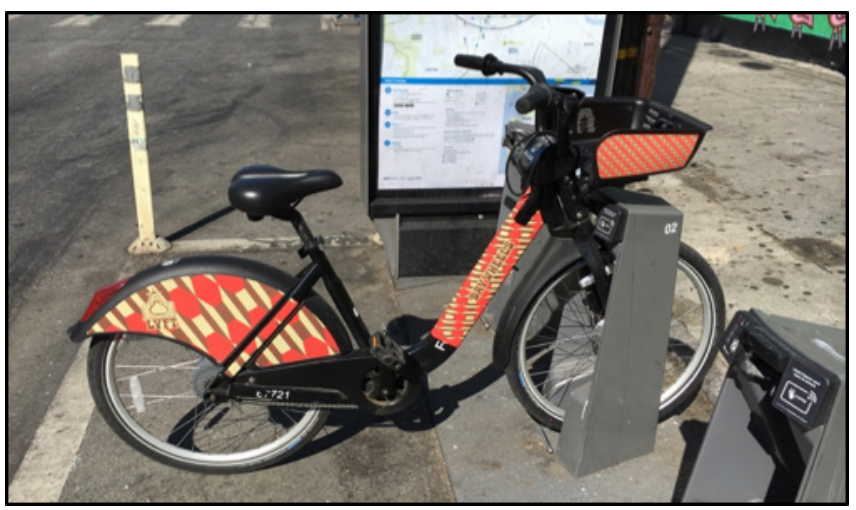

Figure 2. Bay Wheels, a station-based bikesharing system in the Bay Area (photo taken by the author)

Shared e-scooters have a more complicated history; in March, 2018 several e-scooter operators deployed hundreds of vehicles in the city prior to receiving regulatory approval (Pender, 2018). By June of that year, San Francisco passed a law banning all e-scooters on public property, and thereafter initiated an e-scooters permit application (Sulek, 2018). After receiving 12 submissions from operators (Said \& Cabanatuan, 2018), the city awarded two permits, to Skip and Scoot (Jose, 2018). Both e-scooters and JUMP's e-bikes operate in floating formats with geofences.
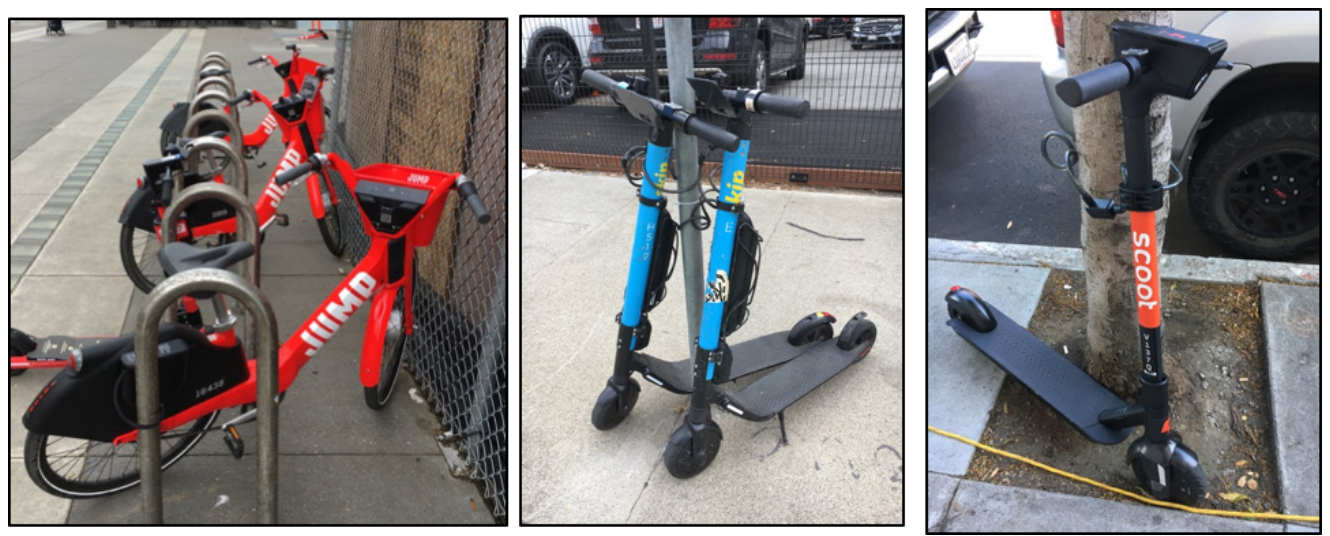

Figure 3. JUMP e-bikes (left), Scoot e-scooters (middle), and Skip e-scooters (right) in San Francisco, CA, all models pictured as of September, 2019 (photos taken by the author)

In terms of regulatory arrangement, each service type (station-based bikeshare, floating bikeshare, and floating e-scooters) maintain different relationships to the City and County of San Francisco. Bay Wheels has an exclusive contract to manage station-based bikeshare in the Bay Area, which includes negotiations with cities as to where stations are located. JUMP, following a pilot in 2017, was awarded a floating bikeshare permit by the city's transportation agency, SFMTA (Bracco, 2018; Hammerl, 2018). Finally, Skip and Scoot were also permitted by SFMTA under the city's initial shared e-scooter pilot.

Between 2017 and 2019 this mix entailed multiple geofences: those for JUMP, Scoot, and Skip. ${ }^{3}$ These mobility options pose different challenges to cities than those with a single scheme: how should these services be regulated spatially? Should there be any attempt to coordinate how different geofences

\footnotetext{
${ }^{3}$ Bay Wheels did create a geofence for its floating e-bikes, though mechanical issues kept these vehicles unavailable for much of this study period, which is why it is not included in this analysis.
} 
relate to each other (including e-scooters to bikes, or station-based bikeshare with floating bikeshare)? Given these pressing questions, the specific goals of this study are to spatially analyze all geofences in San Francisco between 2017 and 2019 (both across and within brands), evaluate how they relate to regulations via a document review of permit guidelines and operator applications, and review the ways in which community organizations have also influenced these boundaries.

Geofences were viewed within each smartphone application, and then hand digitized using the Carto mapping platform on a street-by-street basis to ensure accurate georeferencing (see Figure 4).
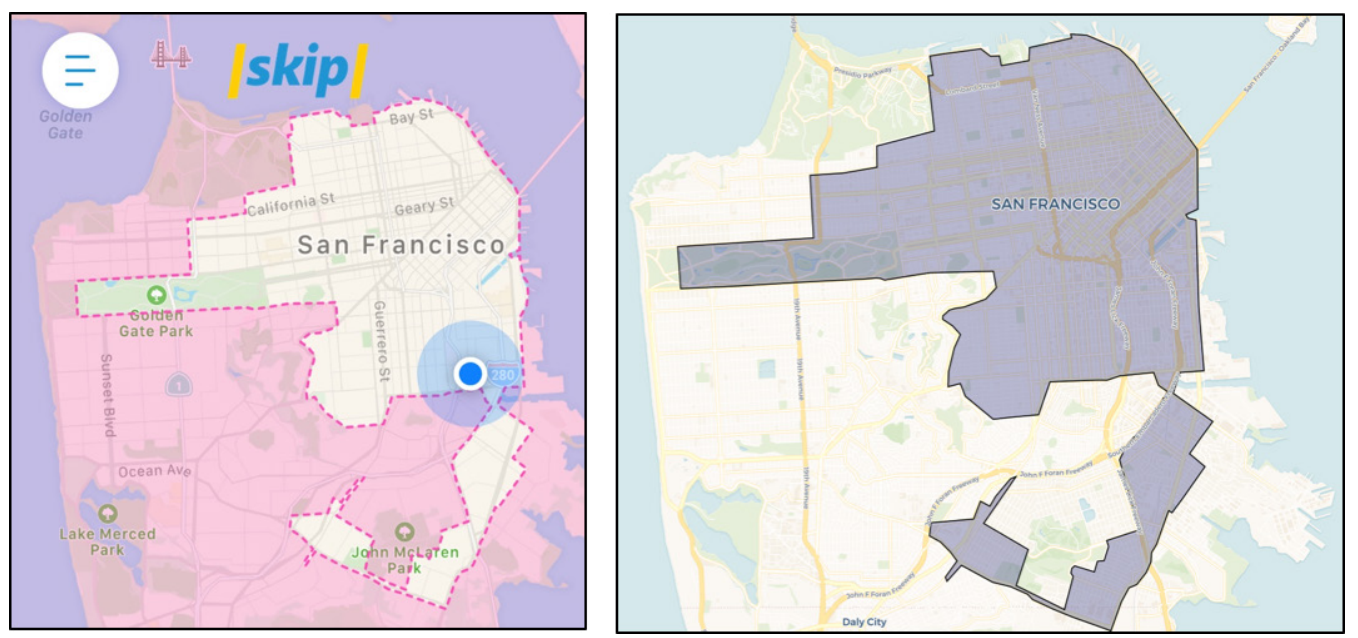

Figure 4. Example outcome of manually digitizing a shared e-scooter geofence sourced from a smartphone application (left) into a GIS polygon layer (right)

While time-consuming, manual digitalization of geofences provides several benefits. First, it allows for spatial comparisons both across operators at the same point in time, and across time for a single operator. As to the level of cartographic accuracy, the hand-digitized versions likely contain minute differences compared to the originals, though those do not alter the analyses made here, including considerations of overall geofence shape, and neighborhood coverage. Each geofence was checked on a monthly basis between June 2017 and September 2019.

Beyond geofence tracking, this study also involved a document review of municipal permit guidelines for shared bikes and e-scooters provided by SFMTA, as well as all submitted permit applications by operators. Shared e-scooter permit applications (including those for both Skip and Scoot) were posted online by SFMTA. While SFMTA's floating bikeshare permit guidelines were also posted online, a public-records request was made in order to obtain JUMP's application. These documents were reviewed under a content-analysis framework, with attention paid to language relating to geographic coverage, which SFMTA refers to as "service areas." Given this, all documents were searched for the keywords "service area," as well as other synonymous terms used by operators such as "blue zone," which was used by Scoot. Those sentences were tagged, and reviewed for mentions of geofence size, placement, shape, coverage of specific neighborhoods, relation to equity, and growth/expansion or change. This sheds light both on how operators in San Francisco devise geofences, as well as how SFMTA advises permit applicants on its broader mobility goals.

Finally, news reports from San Francisco media outlets (San Francisco Chronicle, San Francisco Examiner, and eight neighborhood-specific newspapers) were queried for mentions of shared bike and e-scooters between 2017 and 2019, and stories were sorted by their relevance to geofences. This process identified several instances of community organizations mobilizing to either oppose or support the expansion of geofences within San Francisco, which represent another form of influence beyond operator 
intent and regulatory constraints. The synthesis of these three approaches (spatial analysis of geofences, study of the geofence decision-making process, and review of external events) results in a rich picture of how these new modes cover San Francisco, and leads to implications for regulators and operators in similar circumstances globally.

\section{$4 \quad$ Results}

There are three categories of results: spatial analysis of shared bike and e-scooter geofences in San Francisco between 2017 and 2019, review of SFTMA permitting documents for those modes, including submitted applications, and evidence of nonprofit actors influencing geofences.

\subsection{Bike and e-scooter geofences in San Francisco}

Tracking shared bike and e-scooter geofences in San Francisco between 2017 and 2019 reveals an initial concentration of coverage within the northeast quadrant of the city (including the CBD), followed by incremental growth westward and southward through the fall of 2019. This is evident by comparing geofences across time for individual operators (Figure 5).

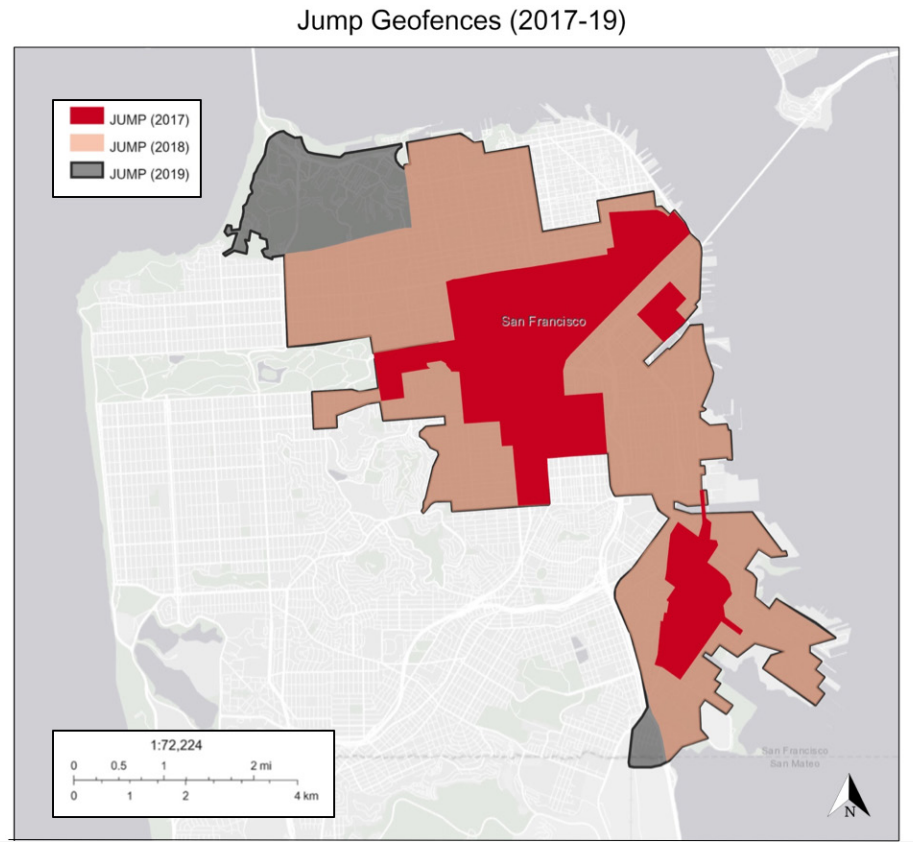

Figure 5a. Longitudinal geofence tracking for JUMP e-bikes (2017-2019) 


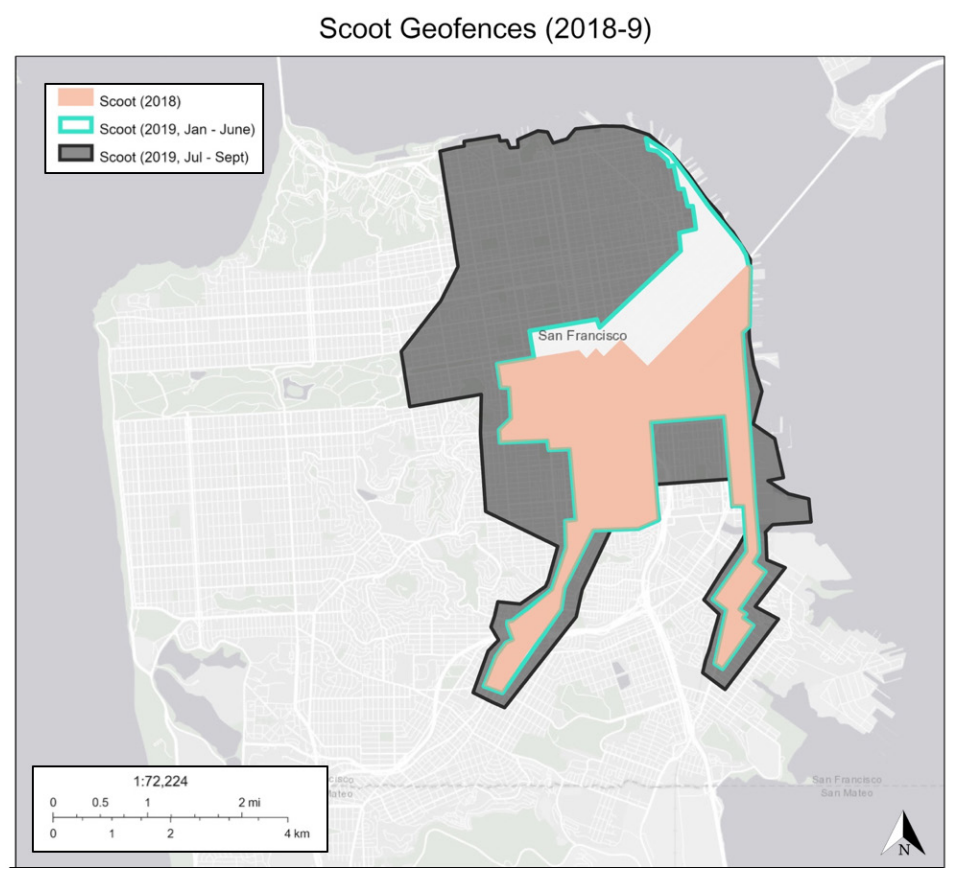

Figure 5b. Longitudinal geofence tracking for Scoot e-scooters (2018-2019)

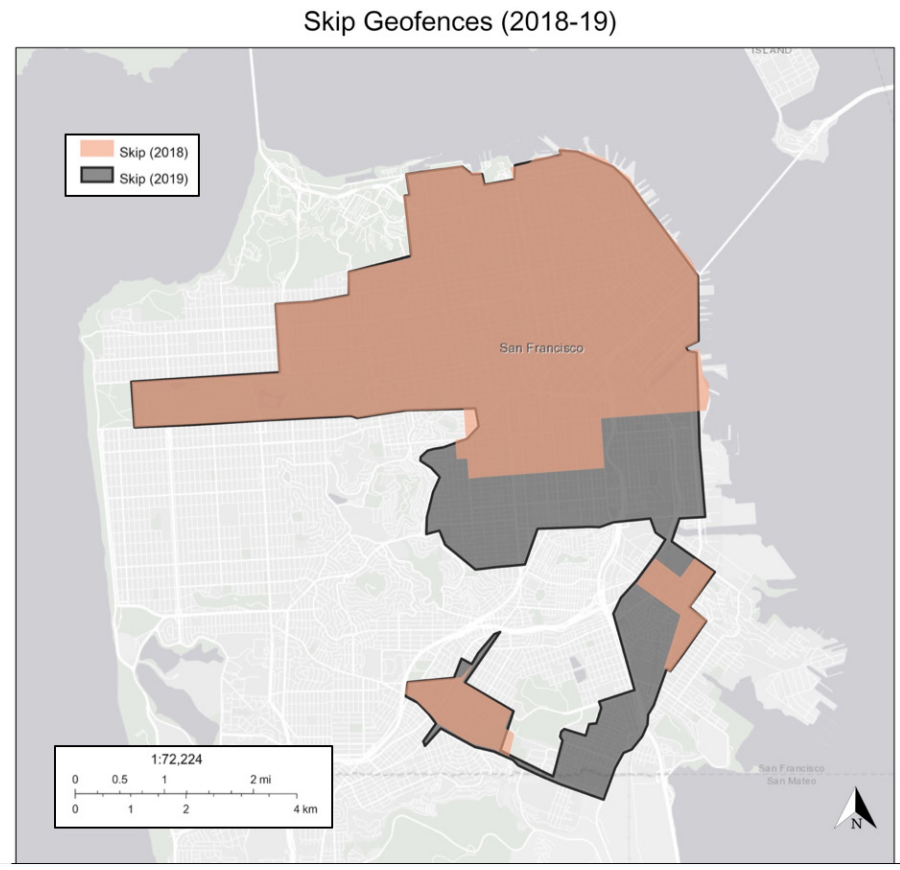

Figure 5c. Longitudinal geofence tracking for Skip e-scooters (2018-2019)

Over this timeframe, each operator expanded their geofence. Specifically, no changes resulted in the removal of any area from prior geofences, and two operators (JUMP and Skip) connected areas in newer geofences that were previously disconnected (which could be thought of as geofence "islands"). JUMP's geofence grew significantly between its initial pilot in 2017 and its permitted service in 2018, but its subsequent expansion in 2019 only added two new areas thereafter: the Presidio (a large park in the northwest corner of San Francisco), and a commuter-rail station in the southeast corner. Skip ex- 
panded from its initial geofence southward to include residential neighborhoods and several commercial districts. Similarly, Scoot's second geofence (in early 2019) expanded northward into the city's CBD and along the waterfront (an area popular with tourists), and its third geofence (in summer 2019) covered the entire northeast quadrant of the city as well as larger portions of the southeast quadrant. Though, it still maintained a pronged or upside-down " $U$ " shape leaving a large gap in the middle of its southern coverage. Similarly, Skip's final geofence in San Francisco (its permit was not renewed at the close of 2019) nearly encircled the city's southeast quadrant, though maintained a large gap in the middle of it.

\subsection{Permit documents for bike and e-scooter services in San Francisco}

This second category of results reviews permit guidelines and submitted applications to understand the relationship between the regulatory framework imposed by SFMTA and resulting geofences. In San Francisco, SFMTA maintains jurisdiction over companies which provide transport services, including shared bike and e-scooters (as well as over roadways, curbs, and transit). ${ }^{4}$ They regulate these operators via competitive permit processes, which differ by mode (e.g., bikes vs. e-scooters). One component of permit guidelines relates to the spatial availability of shared vehicles. SFMTA's "Stationless Bikeshare Program Permit Application" (SFMTA, 2017b), contains a stipulation relating to geofences, or what it refers to as the "service area." It requires that:

At least $20 \%$ of overall bicycle availability shall be maintained within groups of census tracts designated as "communities of concern" (CoCs) by the Metropolitan Transportation Commission, calculated by the total number of bicycles located in CoCs multiplied by the minutes they are available for hire between the hours of 6:00 am and 10:00 pm, divided by the total number of bicycles in service times minutes available throughout the service area.

This indicates two SFMTA criteria for bikeshare geofences; first, they must in some way include communities of concern (CoCs), established by MTC as those census tracts which have a concentration of both minority and low-income households, or a combination of households with limited English proficiency, zero-vehicles, residents 75 years or older, persons with disabilities, single-parent families, or those severely rent-burdened. For the Bay Area, CoCs are re-assessed by a regional equity working group as part of each long-range planning cycle, and such areas have been used in microsimulation models estimating mobility and accessibility of different populations (Castiglione et al., 2006), as well as assessing modal equity (Golub \& Martens, 2014).

Second, the availability of bikes in included CoCs must always represent at least $20 \%$ of the entire fleet (across specific hours of the day). While the permit covers a number of other topics (such as data sharing, insurance, and maintenance, among others), there is no other mention of the "service area," other than that operators must submit a file containing the planned geofence at launch, as well as planned expansions. Thus, the CoC-availability threshold is the only guidance from SFMTA on how geofences should be set. Moreover, the requirement is quite broad; technically a permitted operator need only include a single $\mathrm{CoC}$, as long as it meets the vehicle availability threshold.

SFMTA's floating e-scooter permit, released a year later, offers even less guidance to operators on geofences (Powered e-Scooter Share Program Permit Application (SFMTA, 2018)). Indeed, its “Scooter

\footnotetext{
${ }^{4}$ Transportation Network Companies (TNCs), including Uber and Lyft, are regulated at the state level by the California Public Utilities Commission.
} 
Availability and Service Area" section only asks applicants: "how many scooters would you deploy in different portions of the service area, including disadvantaged communities?" Interestingly, the CoCs availability threshold is not present. Why this metric for equity changed is not obvious, nor is what definition should be used by operators to identify disadvantaged communities.

In addition to the limited guidance on geofences, submitted applications provide an opportunity to understand the operator perspective. JUMP's successful permit application does mention how its geofence includes CoCs, though vaguely, stating that one of the system's goals is to "Create an Equitable and Useful System Area," which is:

Heavily focused on geographic equity...The area provides significant coverage of communities of concern... We are committed to continuing and expanding our service in these areas and will be discussing further useful expansions to additional Communities of Concern with community groups and district Supervisors. (JUMP: A Social Bicycles Project (SFMTA, 2017a))

There are very few specific as to which CoCs JUMP covers, what percent of the total geofence area includes $\mathrm{CoCs}$, or what specific expansions are planned. Similarly, in regards to the two successful escooter applications, Scoot does not specify where its geofence would expand to, only that expansion of its "blue zone" would occur if the vehicle cap is lifted:

During Phase II (ideally launching an additional 1,250 mini-scoots), our planned blue zone will extend much further into our existing service area for electric mopeds as well as areas of the city not currently served by Scoot. (Scoot, 2018)

In contrast, Skip provides more specifics, first dividing San Francisco into four quadrants (subdivided by neighborhood). They also state that the reason their initial geofence does not include all four quadrants is because of the vehicle cap:

However, because 350-500 e-scooters is still below saturation for this market, Skip does not believe it reasonably can blanket all four zones [quadrants], and does not believe in making a false promise in order to obtain a permit. Instead, we have proposed a measured deployment in the Northwest and Southeast zones. (Skip, 2018)

Both of these e-scooter applications addressed the imposed vehicle cap. From Skip's perspective, such a limit on the number of vehicles that can be on the streets at once means that establishing too large a geofence would result in low vehicle densities, which could undermine the system's attractiveness. Thus, the imposition of a vehicle cap on operators is an indirect way that SFMTA influences geofences, particularly their size. Overall, SFMTA mentions geofences only sparingly in both its e-scooter and bike permit guidelines, and varies the equity requirement, both in terms of terminology (CoCs vs. disadvantaged communities), and how they must be covered (using an equation for shared bikes but nothing quantitative for e-scooters). Although geofences are a fundamental feature of the accessibility of micromobility, there is little in the way of instruction or incentives as to how such areas should be drawn.

With this context, geofences were spatially analyzed in relation to San Francisco's CoCs. In Figure 6, those areas are overlaid on the aggregate geofence for 2018 and 2019 - constructed by taking the sum of all geofences for each year - which illustrates that although CoCs in the eastern half of the city do fall within shared bike and e-scooter coverage, those in the western half and on Treasure Island largely do not. Importantly, CoCs spread across San Francisco are not uniform in terms of density, meaning that 
each additional $\mathrm{CoC}$ included in a geofence may affect the overall population of residents now able to use shared bikes or e-scooters differently.

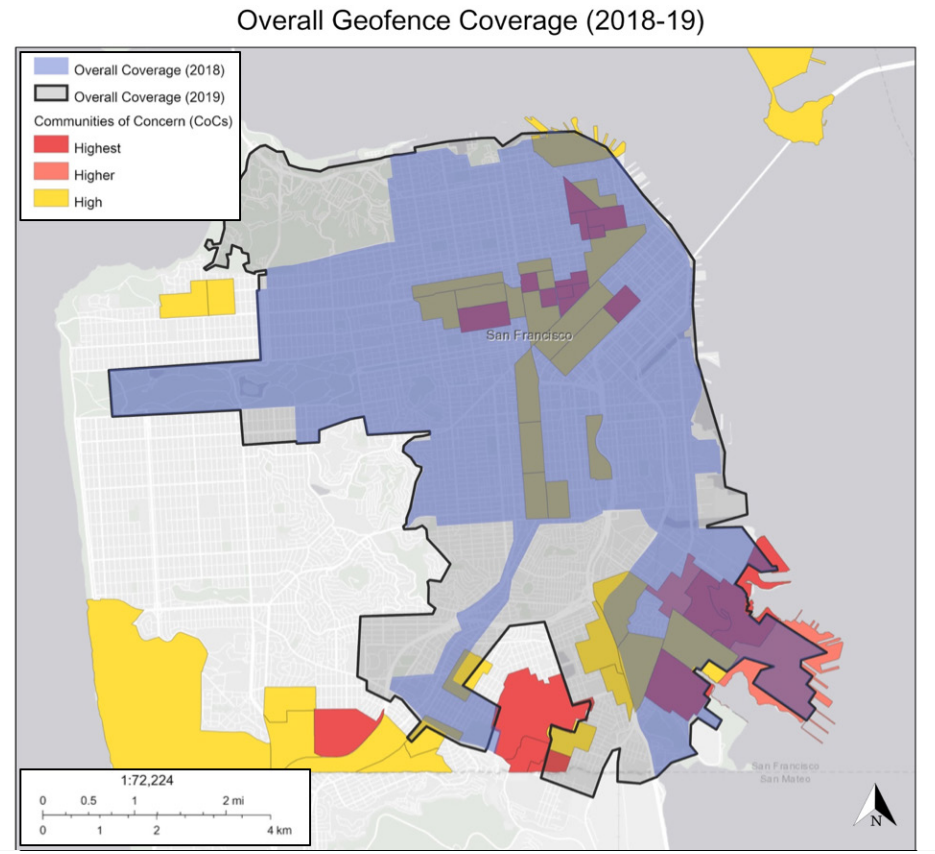

Figure 6. Map of overall geofence coverage, overlaid on San Francisco's Communities of Concern (CoCs) as identified by the regional MPO

\subsection{Influence on geofences by nonprofit actors}

The setting of shared bike and e-scooter geofences is not solely determined by operator preference and SFMTA permit guidelines. In addition to those factors, this section reviews several instances of nonprofit organizations affecting micromobility coverage as well. For context, the expansion of Bay Wheels throughout San Francisco - in terms of the number and spatial extent of stations - has lagged behind announced plans (Brinklow, 2018), in part due to community opposition. Calle 24, a designated Latino Cultural Corridor in the Mission District, has been the site of resistance to Bay Wheels stations from residents and business owners for multiple years (Fitzgerald Rodriguez, 2018; Waxmann, 2017). One component of the arguments voiced is an equation of bikeshare with gentrification (Swan, 2018), a loaded claim which is addressed further in the discussion section. This tactic was evident at a November, 2018 public meeting, during a debate over a proposed Bay Wheels station on a public plaza. This site is relevant to Calle 24 because it represents one end of the corridor, which is often used for cultural events, as well as food and crafts vendors. Eric Arguello, president of a nonprofit organization which advocates on behalf of a number of merchants along this corridor and organizes certain events, provided the following public comment:

This is about economic impacts for the low-income communities and people of color in the Mission. People need these [plazas] to vend in those areas, to supplement those incomes... So this will be an injustice for those stations to take up the space that our vendors are using. (BART, 2018) 
So far this resistance has been successful; no Bay Wheels stations have been installed within Calle 24 , though one was placed just west of the corridor. This station-based history is critical to understand the interaction of geofences with Calle 24. Indeed, digitizing the JUMP e-bike geofence reveals a noticeable square-shaped gap in the Mission District, which tracks precisely to the boundary of Calle 24 (see Figure 7). While there was no public meeting on the setting of the JUMP geofence to gauge community sentiment, this "carve-out" of Calle 24 likely demonstrates mindfulness on the part of the operator to avoid an area that had already opposed bikeshare. Though, not all shared bike and e-scooter operators proceeded in this manner; both Scoot and Skip included Calle 24 in their geofences.

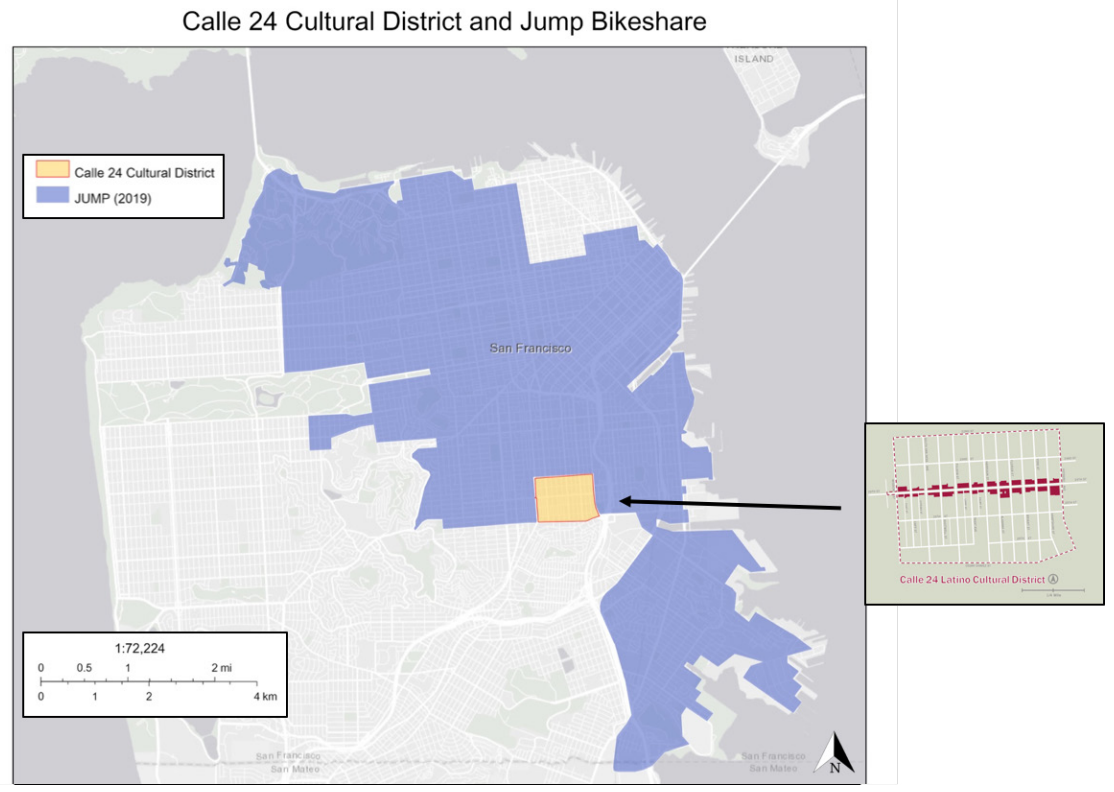

Figure 7. The map of the Calle 24 Cultural District (right), and the JUMP geofence (left), which omits the district entirely (as of September 2019)

In 2019, Scoot established virtual no-parking-zones (areas on the map where ending trips was not allowed) in two lower-income neighborhoods, San Francisco's Chinatown and Tenderloin. Such a use of restrictive geofences within its larger coverage area seemingly undermined its permit application which promised equitable access as a primary goal (Bhuiyan, 2019). In the aftermath of an LA Times article on this issue (which was shared widely online), Scoot removed one of the no-parking-zones (the Tenderloin one), and also released a letter which showed they had been asked by a local organization to limit e-scooter trips within Chinatown (Fitzgerald Rodriguez, 2019). This represents another example of a community, via a local nonprofit, effectively removing itself from e-scooter service even when it lies within an operator's geofence. Organizing against shared bikes and e-scooters is critical to include in an analysis of geofences, because such actions complicate both the tasks of operators and regulators, given the former must consider community responses to its services before launching, and the latter must reckon with the fact that communities of concern requirements may face pushback from those very communities.

In response to these types of opposition, several organizations have worked to accelerate micromobility's expansion. This includes the San Francisco Bicycle Coalition (SFBC) which counts 10,000 members, and a smaller, short-lived group called "Our Bikes." While SFBC advocates on a range of bicycling issues, including bike-lane construction (Matier, 2019), Our Bikes was formed in 2018 by a handful of San Francisco residents for the explicit purpose of increasing the number of Bay Wheels stations, and 
lifting JUMP's vehicle cap (Rudick, 2018b). To those ends, Our Bikes - while maintaining a loose organizational structure - mobilized bikeshare users in San Francisco to sign petitions, contact local officials, and appear at public meetings to provide comment in support of bikeshare growth. The emergence of Our Bikes as a bikeshare booster indicates the rising importance of these modes to residents and commuters, and increased parity in the advocacy campaigns regarding micromobility.

\section{$5 \quad$ Discussion and conclusion}

Digitizing shared bike and e-scooter geofences in San Francisco between 2017 and 2019 reveals spatial patterns in operator preference, as well as expansions in overall coverage over time. First, all shared bike and e-scooter operators were present in the city's dense northeast quadrant, including its CBD. Second, many areas outside that quadrant - which are lower density and primarily residential - did not have access to these shared vehicles. In addition, many geofences exhibited shapes which seem at odds with a well-functioning system, including disconnected pieces (geofence "islands"), and sections which surround certain neighborhoods yet do not include them.

An insight from this spatial analysis and document review is that SFMTA's regulatory approach does not challenge the preference of operators in centering geofences in San Francisco's dense northeast quadrant (where transit is also most present), nor does it prevent the absence of geofences in many of the city's western and southern neighborhoods. Geofence design is mentioned sparingly in permit guidelines, and how these polygons should relate to equity (such as in their inclusion of disadvantaged neighborhoods) is inconsistent. Indeed, there is no coordination of geofences taking place across modes on the part of SFMTA. For example, nothing in the floating bikeshare permit references shared e-scooters, or vice versa. Because the only stated spatial criteria from SFMTA is inclusion of CoC's or disadvantaged communities, all other characteristics such as size, placement, and connectivity (lack of geofence "islands") were left solely to the operator's discretion.

A counter argument to the criticism of these geofences is that for shared bike and e-scooter systems to be financially viable, they must restrict their coverage to dense areas. In this vein, the neighborhoods in San Francisco left out from geofences between 2017-2019 were those with lowest densities and farthest from employment centers. This tension is central to municipal regulation of micromobility, which highlights the conflicting aims of private operators (create a geofence which generates high ridership and reliable profits) and municipalities (ensure shared bikes and e-scooters reach as many residents as possible). Indeed, though the western half of San Francisco is car-centric, this is also precisely the feature that may make a city want shared bikes and e-scooters to be extended there. As to the question of if scooters can reduce car travel in lower-density areas, surveys of scooter riders in Santa Monica, CA and Portland, OR (both cities less dense than San Francisco), do indicate that a large percentage of trips are replacing those which would have been made by car (49\% and 34\%, respectively) (Kozar, 2019; Orr \& Nebel, 2019). However, more research is needed in terms of how shared bikes and e-scooter ridership differs with density and neighborhood type (including trip length, rider demographics, and trip purpose).

Clearly, geofences are not drawn or regulated in a vacuum, as opposition from community groups can modify plans for bikeshare stations and lead to gaps in geofences. These actions must be couched into the broader debate on the politics of urban mobility. Negative reactions to bike infrastructure from different interests have been common enough to coin the term "bikelash," which includes a range of responses to cities embracing cycling, either through new bike lanes or the adoption of bikeshare (Goodyear, 2014; Wild, Woodward, Field, \& Macmillan, 2018; Zavestoki, 2014). Part of the bikelash to Bay Wheels may be linked to the system's origin, when stations were clustered in higher-income and gentrifying neighborhoods, which could have solidified its identity as a transportation mode for the wealthy.

However, there are also reasons that shared bikes and e-scooters can be beneficial to low-income 
communities and communities of color. First, low-income Americans on average own fewer motor vehicles (Blumenberg \& Pierce, 2012; Dargay, 2001), which indicates that micromobility could provide transportation for a number of trips - including commuting - at lower prices than car ownership. Second, low-income travelers also use transit at higher rates (Clark, 2017), and studies so far of shared bikes and e-scooters suggest that they can fill first and last-mile connection gaps (Barnes, 2019). Furthermore, there is also evidence that residents of these communities desire access to shared bikes and e-scooters, which was voiced at a public open house SFMTA held at the midway point of its e-scooter pilot in April, 2019. Specifically, open-house attendees from the Bayview neighborhood (a CoC in San Francisco's southeast quadrant) noted their appreciation for being included in Scoot's initial geofence. Data from SFMTA's "Powered Scooter Share Mid Pilot Evaluation" confirm this, reporting that $52 \%$ of all trips in the program's first six months began or ended in a CoC (SFMTA, 2019). Beyond San Francisco, a large national sample surveyed on their perception of e-scooters found that participants in the two lowest income quantiles viewed e-scooters most favorably (Clewlow, 2018), and a survey in Tempe, Arizona found that African-American and non-white Hispanic respondents were more likely than white respondents to intend to try out e-scooters (Sanders, Branion-Calles, \& Nelson, 2020).

Finally, transportation equity is a multi-faceted concept that cannot be encapsulated solely by spatial analyses. Other aspects, including scheme pricing (Goodman \& Cheshire, 2014), gender and racial diversity (Ji et al., 2017; McNeil, Dill, MacArthur, Broach, \& Howland, 2017; Winters et al., 2019), vehicle accessibility, resolving language and technological barriers (such as limited access to smartphones), and ensuring diverse participation in the planning process (Hannig, 2016) determine how equitable any transportation option will be. This study does not discount the importance of those attributes of shared bikes and e-scooters, but examines the role that geofences play in shaping one fundamental component of accessibility and equity. Indeed, much further study is needed into these manifold aspects of equity for micromobility, including how they relate to and are shaped by geofence decisions.

Should broad geofence coverage be a municipal goal, there are several recommendations that can be made to cities based on this study. First, without geofence-specific regulations in place, operators will concentrate their services in central business districts and surrounding dense neighborhoods. This may be beneficial to certain residents, commuters, and tourists, but if cities intend vehicles to reach beyond such places, permits must provide clear guidance to that effect. For those seeking broader coverage, leverage the permit process as a way to raise the salience of geofence design to potential operators. This could be done via stated preferences on geofence size (e.g., $70 \%$ of the city) or functionality (e.g., no geofence "islands"). Second, cities could devise incentives that link geofences to vehicle caps. Operators understandably fear a geofence-size requirement if vehicle caps are held constant, which would entail sub-optimal densities of vehicles. To avoid this, cities could create a sliding scale that offers a higher number of vehicles for larger geofences, which could mollify fears from operators regarding scooter density. As to incentives, there are also levers to pull in terms of reduced fees or taxes on operators which propose larger geofences. Such approaches recognize the financial trade-offs operators are making when designing geofences in the first place.

As for the limitations of this study, tracking only geofences leaves out other aspects of shared bike and e-scooter availability. Indeed, it matters little if a neighborhood is covered by a geofence if no vehicles are present on its streets to ride. Thus, an open question this study raises is how geofence size and placement relates to vehicle-fleet caps. A finding of this paper - via the document review process - is that the vehicle cap is a factor affecting how operators draw geofences to begin with. Furthermore, other cities have taken different approaches to geographic constraints on shared bikes and e-scooters than San Francisco, and it is crucial to explore if those strategies lead to better outcomes. Just across the Bay, Oakland mandates that all e-scooter operators cover the entire city's road network, in effect removing operator discretion from geofence setting. These two cities represent an important contrast in regulations, and 
should be studied comparatively going forward. This is particularly true in regards to the interplay of vehicle caps and geofence size; Oakland's original e-scooter permit limited operators to 1,000 scooters (Said, 2019), which perhaps may expand over time based on community feedback or if certain equity thresholds are met.

Moreover, much more work is needed to understand individuals perceptions as to barriers of using shared bikes and e-scooters, including how geofences factor into travel behavior. This study uses a review of local media outlets as a proxy for community opposition to the spatial coverage of shared bikes and scooters, but such a method likely leaves out other instances of resistance to micromobility in San Francisco. It also does not account for sentiment on geofences (positive or negative) among individuals that does not rise to the level of an organized response. For these reasons, future research should probe - via surveys, interviews, and focus groups - how residents from a range of backgrounds perceive geofences.

Of course, there are legitimate reasons to challenge spatial regulation of shared biked and e-scooters overall, such as policies which limit the size of geofences or force them to expand. In terms of private businesses of other kinds (restaurants, boutiques, etc.), there are rarely public-sector directives on where such an entity must be present. Though, the history of urban transportation in the United States - including when it was largely provided by private companies in the late 19 th and early 20 th centuries - includes numerous examples of municipalities negotiating service levels and spatial extents in exchange for permits to operate (Jackson, 1985; Xie \& Levinson, 2009). The logic of those times was that the right to operate a transportation service in the public right of way was a privilege that came with it certain obligations to service quality and geographic reach. Whether and how that logic persists to the current day with micromobility, particularly in regards to geofence requirements and incentives, is a rich area for research.

\section{Acknowledgements}

Publication made possible by support from the Berkeley Research Impact Initiative (BRII) sponsored by the UC Berkeley Library.

\section{Data availability}

Data archive available at https://sites.google.com/berkeley.edu/marcelmoran/research/micromobilityin-san-francisco 


\section{References}

Andersson, F., Haltiwanger, J. C., Kutzbach, M. J., Pollakowski, H. O., \& Weinberg, D. H. (2018). Job displacement and the duration of joblessness: The role of spatial mismatch. The Review of Economics and Statistics, 100(2), 203-18. https://doi.org/10.1162/REST_a_00707

Austin Public Health. (2019). Dockless electric scooter-related injuries study. Austin TX: Austin Public Health. Retrieved from https://austintexas.gov/sites/default/files/files/Health/Web_Dockless_Electric_Scooter-Related_Injury_Study_final_version_EDSU_5.14.19.pdf

Barnes, F. (2019). A scoot, skip, and a JUMP away: Learning from shared micromobility systems in San Francisco. Los Angeles: Institute of Transportation Studies, UCLA. https://doi.org/10.17610/T6QP40

BART. (2018). BART Board TV. Retrieved from https://www.bart.gov/about/bod/multimedia

Bauer, F., Riley, J. D., Lewandowski, K., Najafi, K., Markowski, H., \& Kepros, J. (2020). Traumatic injuries associated with standing motorized scooters. JAMA Network Open, 3 (3), e201925-e201925. https://doi.org/10.1001/jamanetworkopen.2020.1925

Bhuiyan, J. (2019, August 15). Scooter startup snubs San Francisco's poorest neighborhood despite promising access. Los Angeles Times. Retrieved from https:/www.latimes.com/business/technology/ story/2019-08-14/san-francisco-scoot-tenderloin-bird

Bliss, L. (2019, April 19). When will the electric e-scooters take over? CityLab. Retrieved from https:// www.citylab.com/transportation/2019/04/electric-scooter-micromobility-transportation-revolution/587440/

Blumenberg, E., \& Ong, P. (2001). Cars, buses, and jobs: Welfare participants and employment access in Los Angeles. Transportation Research Record, 1756(1), 22-31. https://doi.org/10.3141/1756-03

Blumenberg, E., \& Pierce, G. (2012). Automobile ownership and travel by the poor: Evidence from the 2009 National Household Travel Survey. Transportation Research Record, 2320(1), 28-36. https:// doi.org/10.3141/2320-04

Bradshaw, K. (2019, March 19). Daily e-scooter use hits all-time record during SXSW, Austin City data show. Statesman. Retrieved from https://www.statesman.com/news/20190319/daily-scooter-usehits-all-time-record-during-sxsw-austin-city-data-show

Bracco, S. (2018, October 15). With city approval, Jump expands e-bike pilot program. Hoodline (blog). Retrieved from https:/hoodline.com/2018/10/with-city-approval-jump-expands-e-bikepilot-program

Brinklow, A. (2018, August 8). GoBike expansion steers off course [updated]. Curbed San Francisco. Retrieved from https://sf.curbed.com/2018/8/8/17666186/ford-gobike-nimbys-supervisors-bikesdocking-stations-sf

Castellanos, S. (2018, December 21). DC just released the first evaluation of its dockless bike and escooter experiment. TheCityFix (blog). Retrieved from https://thecityfix.com/blog/d-c-just-releasedthe-findings-from-its-dockless-bike-and-scooter-pilot-sebastian-castellanos/

Castiglione, J., Hiatt, R., Chang, T., \& Charlton, B. (2006). Application of travel demand microsimulation model for equity analysis. Transportation Research Record 1977(1), 35-42. https://doi. org/10.1177/0361198106197700105

Clark, H. M. (2017). Who rides public transportation? American Public Transportation Association. Retrieved from https://www.apta.com/wp-content/uploads/Resources/resources/reportsandpublications/Documents/APTA-Who-Rides-Public-Transportation-2017.pdf

Clarke, M., \& Clary, J. (2019, January 14). Explore dockless data with Austin Transportation. Civiqueso (blog). Retrieved from https://medium.com/civiqueso/explore-dockless-data-with-austin-transportation-4a308aa5c18 
Clewlow, R. (2018). The micro-mobility revolution: The introduction and adoption of electric e-scooters in the United States. San Francisco, CA: Populus. Retrieved from https://www.populus.ai/micromobility-2018-july/

Cohen, A., \& Shaheen, S. A. (2016). Planning for shared mobility (PAS 583). Chicago: American Planning Association. Retrieved from https:/www.planning.org/publications/report/9107556/

Dargay, J. M. (2001). The effect of income on car ownership: Evidence of asymmetry. Transportation Research Part A: Policy and Practice, 35(9), 807-21. https://doi.org/10.1016/S0965-8564(00)00018-5

DeMaio, P. (2009). Bike-sharing: History, impacts, models of provision, and future. Journal of Public Transportation, 12(4), 41-56.

Docherty, I., Marsden, G., \& Anable, J. (2018). The governance of smart mobility. Transportation Research Part A: Policy and Practice, 115, 114-25. https://doi.org/10.1016/j.tra.2017.09.012

Everett, H. (2020, May 28). Uber scraps thousands of bikes, Lime acquires JUMP division. Cycling Industry News. Retrieved from https://cyclingindustry.news/uber-scraps-thousands-jump-bikes-acquired-by-lime/

Fang, K., Agrawal, A. W., Steele, J., Hunter, J. J., \& Hooper, A. M. (2018). Where do riders park dockless, shared electric e-scooters? Findings from San Jose, California (Project 1713). San Jose, CA: Mineta Transportation Institute, San Jose State University. Retrieved from https://scholarworks.sjsu.edu/cgi/ viewcontent.cgi?article $=1250 \&$ context=mti_publications

Fishman, E. (2020). Bike share. London: Routledge.

Fitzgerald Rodriguez, J. (2018, August 5). Supes, neighbors block Ford GoBike's citywide expansion. San Francisco Examiner. Retrieved from http://www.sfexaminer.com/supes-neighbors-block-fordgobikes-citywide-expansion/

Fitzgerald Rodriguez, J. (2019, August 16). Did Scoot 'redline' Sf neighborhoods? Chinatown group says, 'We asked for it.' The San Francisco Examiner. Retrieved from https://www.sfexaminer.com/ news/did-scoot-redline-sf-neighborhoods-chinatown-group-says-we-asked-for-it/

García-Palomares, J., Gutiérrez, J., \& Latorre, M. (2012). Optimizing the location of stations in bikesharing programs: A GIS approach. Applied Geography, 35, 235-246. https://doi.org/10.1016/j.apgeog.2012.07.002

Goebel, B. (2013, July 16). Bay area bike share to launch next month. KQED. Retrieved from https:// www.kqed.org/news/103757/bay-area-bike-share-to-launch-next-month

Golub, A., \& Martens, K. (2014). Using principles of justice to assess the modal equity of regional transportation plans. Journal of Transport Geography, 41, 10-20. https://doi.org/10.1016/j.jtrangeo.2014.07.014

Goodman, A., \& Cheshire, J. (2014). Inequalities in the London bicycle sharing system revisited: Impacts of extending the scheme to poorer areas but then doubling prices. Journal of Transport Geography, 41, 272-279. https://doi.org/10.1016/j.jtrangeo.2014.04.004

Goodyear, S. (2014, September 15). Why bike lovers should be happy about "bikelash." CityLab. Retrieved from http://www.citylab.com/commute/2014/09/why-bike-lovers-should-be-happy-aboutbikelash/380219/

Giuliano, G. (2005). Low income, public transit, and mobility. Transportation Research Record, 1927(1), 63-70. https://doi.org/10.1177/0361198105192700108

Groth, S. (2019). Multimodal divide: Reproduction of transport poverty in smart mobility Trends. Transportation Research Part A: Policy and Practice, 125, 56-71. https://doi.org/10.1016/j.tra.2019.04.018

Hammerl, T. (2018, January 10). SFMTA issues 1st dockless e-bike sharing permit to JUMP bikes. Hoodline (blog). Retrieved from https://hoodline.com/2018/01/sfmta-issues-1st-dockless-e-bikesharing-permit-to-jump-bikes 
Hannig, J. (2016). Community disengagement: The greatest barrier to equitable bikeshare. In A. Golub, M. L. Hoffman, A. Lugo, \& G. Sandoval (Eds.), Bicycle justice and urban rransformation: Biking for all? (pp. 210-22). Abingdon-on-Thames: Taylor \& Francis Group. Retrieved from https://ebookcentral-proquest-com.libproxy.berkeley.edu/lib/berkeley-ebooks/detail.action?docID=4595322\#

Hoffmann, M. L. (2016). Bike lanes are white lanes: Bicycle advocacy and urban planning. Lincoln, NE: University of Nebraska Press. Retrieved from http://muse.jhu.edu/book/45847/

Hollingsworth, J., Copeland, B., \& Johnson, J. X. (2019). Are e-e-scooters polluters? The environmental impacts of shared dockless electric e-scooters. Environmental Research Letters, 14(8), 084031. https://doi.org/10.1088/1748-9326/ab2da8

Jackson, K. T. (1985). Crabgrass frontier: The suburbanization of the United States. New York: Oxford University Press.

Ji, Y., Fan, Y., Ermagun, A., Cao, X., Wang, W., \& Das, K. (2017). Public bicycle as a feeder mode to rail transit in China: The role of gender, age, income, trip purpose, and bicycle theft experience. International Journal of Sustainable Transportation, 11(4), 308-317. https://doi.org/10.1080/15568 318.2016.1253802

Jose, B. (2018, August 30). SFMTA offers two permits for one-year powered e-scooter pilot. SFMTA. Retrieved from https://www.sfmta.com/blog/sfmta-offers-two-permits-one-year-powered-scooterpilot

Kabra, A., Belavina, E., \& Girotra, K. (2019). Bike-share systems: Accessibility and availability. Management Science, 66(9), 3799-3801. https://doi.org/10.1287/mnsc.2019.3407

Kodransky, M., \& Lewenstein, G. (2014). Connecting low-income people to opportunity with shared mobility. IDTP/Living cities. Retrieved from https:/www.itdp.in/wp-content/uploads/2016/06/ Shared-Mobility_Full-Report.pdf

Kozar, K. (2019). Shared mobility pilot program summary report. Santa Monica, CA: City of Santa Monica. Retrieved from https://www.smgov.net/uploadedFiles/Departments/PCD/Transportation/ SantaMonicaSharedMobilityEvaluation_Final_110419.pdf

Lazarus, J., Pourquier, J. C., Feng, F., Hammel, H., \& Shaheen, S. A. (2020). Micromobility evolution and expansion: Understanding how docked and dockless bikesharing models complement and compete - A case study of San Francisco. Journal of Transport Geography, 84, 102620. https://doi. org/10.1016/j.jtrangeo.2019.102620

Liu, D., \& Kwan, M. P. (2020). Measuring spatial mismatch and job access inequity based on transitbased job accessibility for poor job seekers. Travel Behavior and Society, 19, 184-93. https://doi. org/10.1016/j.tbs.2020.01.005

Lohry, G. F., \& Yiu, A. (2015). Bikeshare in China as a public service: Comparing government run and public-private partnership operation models. Natural Resources Forum, 39(1), 41-52. https://doi. org/10.1111/1477-8947.12063

Lugo, A. E. (2018). Bicycle/race: Transportation, culture, and resistance. Portland, OR: Microcosm Publishing.

Lyft. (2019, June 11). Introducing bay wheels: New bikes and a new name. Lyft Blog (blog). Retrieved from https://blog.lyft.com/posts/introducing-bay-wheels-new-bikes-and-a-new-name

Marshall, A. (2018, April 9). Uber acquires the bike-share company jump. WIRED. Retrieved from https://www.wired.com/story/uber-acquires-jump-bike/

Matier, P. (2019, November 17). Bikes still aren't a preferred means of travel. Can the city change that? San Francisco Chronicle, Local Section. Retrieved from https://www.sfchronicle.com/bayarea/philmatier/article/In-SF-bikes-still-aren-t-a-preferred-means-of-14865212.php

Mattioli, G. (2016). Transport needs in a climate-constrained world. A novel framework to reconcile social and environmental sustainability in transport. Energy Research \& Social Science, 18, 118-28. 
https://doi.org/10.1016/j.erss.2016.03.025

McKenzie, B. S. (2013). Neighborhood access to transit by race, ethnicity, and poverty in Portland, OR. City \& Community, 12(2), 134-55. https://doi.org/10.1111/cico.12022

McKenzie, G. (2020). Urban mobility in the sharing economy: A spatiotemporal comparison of shared mobility services. Computers, Environment and Urban Systems, 79, 101418. https://doi. org/10.1016/j.compenvurbsys.2019.101418

McNeil, N., Dill, J. MacArthur, J. Broach, J., \& Howland, S. (2017). Breaking barriers to bike share: Insights from residents of traditionally underserved neighborhoods. Portland, OR: Transportation Research and Education Center, Portland State University. Retrieved from https://pdxscholar.library.pdx.edu/ cgi/viewcontent.cgi?article $=1140 \&$ context=trec_reports

Médard de Chardon, C., Caruso, G., \& Thomas, I. (2017). Bicycle sharing system 'success' determinants. Transportation Research Part A: Policy and Practice, 100, 202-214. https://doi.org/10.1016/j. tra.2017.04.020

Moran, M. E., Laa, B., \& Emberger, G. (2020). Six scooter operators, six maps: Spatial coverage and regulation of micromobility in Vienna, Austria. Case Studies on Transport Policy, 8(2), 658-671. https://doi.org/10.1016/j.cstp.2020.03.001

Orr, B., \& Nebel, E. (2019). 2018 e-scooter findings report. Portland, OR: Portland Bureau of Transportation. Retrieved from https://www.portlandoregon.gov/transportation/article/709719

Pender, K. (2017, June 27). Electric bike-share rides into SF, jumping ahead of Ford GoBike. San Francisco Chronicle. Retrieved from https:/www.sfchronicle.com/business/networth/article/Electricbike-share-rides-into-SF-jumping-ahead-11250951.php

Pender, K. (2018, March 29). E-scooters descend on San Francisco sidewalks. San Francisco Chronicle. Retrieved from https://www.sfchronicle.com/business/article/E-scooters-descend-on-San-Franciscosidewalks-12791871.php

Pierce, G., \& Shoup, D. (2013). Getting the prices right. Journal of the American Planning Association, 79(1), 67-81. https://doi.org/10.1080/01944363.2013.787307

Rudick, R. (2017, July 6). SFMTA requires permit for dockless bike share. Streetsblog San Francisco (blog). Retrieved from https://sf.streetsblog.org/2017/07/06/sfmta-requires-permit-for-docklessbike-share/

Rudick, R. (2018a, January 12). JUMP bikes cleared to launch. Streetsblog San Francisco (blog). Retrieved from https://sf.streetsblog.org/2018/01/11/san-francisco-issues-permit-for-a-non-fordgobike-bike-share/

Rudick, R. (2018b, August 14). Advocates want bike share caps removed. Streetsblog San Francisco (blog). Retrieved from https://sf.streetsblog.org/2018/08/14/advocates-want-bike-share-caps-removed/

Russell, J. (2017, July 12). Meet mobike, a billion-dollar bike-sharing startup from China. TechCrunch (blog). Retrieved from http://social.techcrunch.com/2017/07/12/chinese-bike-sharing-startup-mobike/

Said, C., \& M. Cabanatuan. (2018, June 15). Scooter firms' SF permit applications revealed: They promise to behave. San Francisco Chronicle. Retrieved from https:/www.sfchronicle.com/business/ article/The-12-scooter-companies-that-plan-to-roll-12999364.php\#

Said, C. (2019, July 2). Oakland OKs 3,500 rental e-scooters from bird, lime, Lyft, clever. San Francisco Chronicle, Business Section. Retrieved from https://www.sfchronicle.com/business/article/OaklandOKs-3-500-rental-e-scooters-from-Bird-14067377.php

Sanders, R. L., Branion-Calles, M., \& Nelson, T. A. (2020). To scoot or not to scoot: Findings from a recent survey about the benefits and barriers of using e-scooters for riders and non-riders. Transportation Research Part A: Policy and Practice, 139, 217-227. https://doi.org/10.1016/j.tra.2020.07.009 
Scoot. (2018). SFMTA powered scooter share program permit application. SFMTA. Retrieved from https:// www.dropbox.com/s/lvyr047detbzirw/Scoot_2018_Permit_Application.pdf?dl=0

SFMTA. (2017a). JUMP: A social bicycles project. SFMTA, stationless bikeshare program permit application $v 3$ (p. 41). San Francisco, CA: SFMTA.

SFMTA. (2017b). Stationless bikeshare program permit application. San Francisco, CA: San Francisco Municipal Transportation Agency. Retrieved from https://www.sfmta.com/sites/default/files/projects/2017/Bike\%20Share\%20Permit_v1.1_FINAL.pdf

SFMTA. (2018). Powered e-scooter share program permit application. SFMTA. Retrieved from https:// www.dropbox.com/s/mb2ftrn4pvnefhd/SFMTA_Scooter_Application_2018.pdf?dl=0

SFMTA. (2019). Powered scooter share mid-pilot evaluation. San Francisco, CA: San Francisco Municipal Transportation Agency. Retrieved from https:/www.sfmta.com/sites/default/files/reports-and-documents/2019/08/powered_scooter_share_mid-pilot_evaluation_final.pdf

Shaheen, S. A., Guzman, S., \& Zhang, H. (2010). Bikesharing in Europe, the Americas, and

Asia: Past, present, and future. Transportation Research Record: Journal of the Transportation Research Board, 2143(1), 159-167. https://doi.org/10.3141/2143-20

Shaheen, S. A., Martin, E., Chan, N. D., Cohen, A. P., \& Pogodzinski, M. (2014). Public

bikesharing in North America during a period of rapid expansion: Understanding business models, industry trends and user impacts. San Jose, CA: Mineta Transportation Institute, San Jose State University. Retrieved from https://transweb.sjsu.edu/sites/default/files/1131-public-bikesharing-business-modelstrends-impacts.pdf

Shaheen, S. A., \& Cohen, A. (2019). Shared micromoblity policy toolkit: Docked and dockless

bike and e-scooter sharing. Berkeley, CA: Transportation Sustainability Research Center, University of California. Retrieved from https://escholarship.org/uc/item/00k897b5

Sherwood, K., \& Murphy, J. (2014). Expanding a municipal bikeshare system into an urban national park through community partnerships: City of San Antonio, Texas, and San Antonio Missions National Historical Park. Transportation Research Record, 2453(1), 54-61. https://doi. org/10.3141/2453-07

Sikka, N., Vila, C., Stratton, M., Ghassemi, M., \& Pourmand, A. (2019). Sharing the sidewalk: A case of e-scooter related pedestrian injury. The American Journal of Emergency Medicine, 37(9), 1807. e5-1807.e7. https://doi.org/10.1016/j.ajem.2019.06.017

Skip. (2018). SFMTA powered scooter share program permit application. SFMTA. Retrieved from https:// www.dropbox.com/s/klnypnt9284vgd1/Skip_2018_Permit_Application.pdf?dl=0

Smith,C.S.,\&Schwieterman,J.P.(2018).E-scooterscenarios:Evaluatingthepotentialmobilitybenefitsofshared dockless e-scooters in Chicago. Chicago: Chaddick Institute, DePaul University. Retrieved from https:// las.depaul.edu/centers-and-institutes/chaddick-institute-for-metropolitan-development/researchand-publications/Documents/E-E-scooterscenariosMicroMobilityStudy_FINAL_20181212.pdf

Smith, C. S., \& Schwieterman, J. P. (2019). A day in the life of Chicagos e-scooter pilot

program. Chicago: Chaddick Institute, DePaul University. Retrieved from https://drive.google.com/ file/d/1SJ8MV4UgXtq2ln_mdCFTLCmUrSSHVG6I/view?ts=5d5ad61e

Somenahalli, S. V. C., Meng, L., Sleep, C., \& Berry, S. (2019). Greening inner-urban travel with sharing economy mobility services: Barriers to the provision of shared mobility services. Canberra, Australia: Low Carbon Living, Department of Industry Innovation and Science. Retrieved from https://apo. org.au/sites/default/files/resource-files/2019-06/apo-nid243941.pdf

Sulek, J. P. (2018, April 17). San Francisco impounds electric e-scooters, execs called 'spoiled brats.' San Jose Mercury News, California News. Retrieved from https:/www.mercurynews.com/2018/04/17/ san-francisco-impounds-electric-e-scooters-execs-called-spoiled-brats/ 
Swan, R. (2018, November 16). Mission residents decry bike-share dock as gentrification, BART agrees to move it. San Francisco Chronicle, Local Section. Retrieved from https://www.sfchronicle.com/ bayarea/article/Mission-residents-decry-bikeshare-station-as-13395943.php

van der Zee, R. (2016, April 16). Story of cities \#30: How this Amsterdam inventor gave bike-sharing to the world. The Guardian, Cities Section. Retrieved from https://www.theguardian.com/cities/2016/ apr/26/story-cities-amsterdam-bike-share-scheme

Walker, J. (2008). Purpose-driven public transport: Creating a clear conversation about public transport goals. Journal of Transport Geography, 16(6), 436-42. https://doi.org/10.1016/j.jtrangeo.2008.06.005

Waxmann, L. (2017, July 18). Neighborhood group rejects bike share expansion to 24th street.

Mission Local (blog). Retrieved from https://missionlocal.org/2017/07/neighborhood-group-rejectsbike-share-expansion-to-24th-street/

Welch, T. F. (2013). Equity in transport: The distribution of transit access and connectivity among affordable housing units. Transport Policy, 30, 283-293. https://doi.org/10.1016/j.tranpol.2013.09.020

Wild, K., Woodward, A., Field, A., \& Macmillan, A. (2018). Beyond 'bikelash': Engaging with community opposition to cycle lanes. Mobilities, 13(4), 505-519. https://doi.org/10.1080/17450101.2 017.1408950

Winters, M., Hosford, K., \& Javaheri, S. (2019). Who are the 'super-users' of public bike share? An analysis of public bike share members in Vancouver, BC. Preventive Medicine Reports 15 (September): 100946. https://doi.org/10.1016/j.pmedr.2019.100946

Wood, J., Bradley, S., \& Hamidi, S. (2019). Preparing for progress: Establishing guidelines for the regulation, safe integration, and equitable usage of dockless electric scooters in American cities. Arlington, TX: Center for Transportation, Equity, Decisions and Dollars. Retrieved from https://ctedd.uta.edu/wpcontent/uploads/2020/01/wood_final.pdf

Xie, F., \& Levinson, D. (2010). How streetcars shaped suburbanization: A granger causality analysis of land use and transit in the Twin Cities. Journal of Economic Geography, 10(3), 453-470. https://doi. org/10.1093/jeg/lbp031

Yanocha, D., Mason, J., Patlan, M., Benicchio, T., Alfred, I., \& Laksmana, U. (2018). The bikeshare planning guide. New York: Institute for Transportation and Development Policy. Retrieved from https://itdpdotorg.wpengine.com/wp-content/uploads/2013/12/BSPG_digital.pdf

Yurieff, K. (2018, July 2). Lyft acquires Citi Bike parent company, Motivate. CNN Money. Retrieved from https://money.cnn.com/2018/07/02/technology/lyft-bikeshare-motivate/index.html

Zavestoski, S. (2014, July 16). Bicycling and the "cyclist identity": Understanding the "bikelash." Retrieved from https:/invisiblecyclist.com/2014/07/16/bicycling-and-the-cyclist-identity-understanding-the-bikelash/ 